\title{
A IMPORTÂNCIA DA AFETIVIDADE NA EDUCAÇÃO DA CRIANÇA
}

\section{THE IMPORTANCE OF THE AFFECTIVITY IN THE CHILD EDUCATION}

\author{
Maria Sueli TURATTI* \\ Alícia Greyce Turatti PESSOLATO ${ }^{\dagger}$ \\ Marília Marinho SILVA
}

\begin{abstract}
"Para haver aprendizagem deve haver troca, e para haver troca, essa troca deve ser permeada de afeto. Precisamos não só ensinar o currículo, mas ensinar a amar, a ter empatia com o outro, e isso só se dá através do afeto e da afetividade. Para isso precisamos da família e do lúdico, pois é a através do lúdico que podemos ensinar com afeto." (DE PAULA E FARIA, 2010)
\end{abstract}

\begin{abstract}
Resumo: A afetividade relacionada ao ensino, principalmente na Educação Infantil e Ensino Fundamental, influencia em toda e qualquer dificuldade de aprendizagem e favorece uma maior receptividade do ensino por parte do alunado, que aprenderá com mais facilidade. Sabendo-se da influência da escola e do professor na formação psicossocial do indivíduo, é de substancial importância a presença de um ambiente escolar acolhedor e de educadores capacitados a exercer adequadamente suas tarefas, porém sensíveis ao transmitir afeto na mais ampla concepção da palavra. Deve-se a isso o fato de que desde o início de sua vida o individuo tenta socializar-se, descobrindo o mundo inclusive pela aprendizagem escolar. Essa tentativa acompanhada de sentimentos de afeto fará com que o mesmo sobressaia-se aos obstáculos com sucesso e realização. Do contrário, o indivíduo poderá não conseguir conquistar autonomia, socialização e conhecimento.
\end{abstract}

Palavras-chave: afetividade, educação, ambiente escolar afetivo, infância.

Abstract: The affectivity related to learning, especially in kindergarten and elementary school, influences on learning disabilities and promotes increased receptivity of the students, who learn more easily. Knowing the influence of the school and teacher in the individual psychosocial formation, it's substantial importance to the presence of a welcoming school environment and teachers trained to adequaly perform their tasks, but sensitive to convey affection in broadest sense of the word. Due to this the fact that since the beginning of his life the individual attempts to socialize, discover the world including of learning school. This attempt accompanied by feelings of affection will make it stand out are the obstacles with success and achievement. Otherwise, the individual may be unable to gain autonomy, socialization and knowledge.

Key-words: affection, education, affective school environment, childhood.

\footnotetext{
* Psicopedagoga e Professora de Educação Infantil e Ensino Fundamental- Centro Universitário da Fundação de Ensino Octávio Bastos - UniFEOB - São João da Boa Vista-SP

${ }^{\dagger}$ Mestre em Ciências - Universidade de São Paulo - USP - São Paulo-SP. Email: aliciagreyce@gmail.com

‡ Professora Doutora em Linguística Aplicada - Universidade Estadual de Campinas - UNICAMP - Campinas-SP.
} 


\section{Introdução}

A afetividade acompanha o ser humano desde o momento da concepção até a morte, passando por todas as fases de desenvolvimento. Na educação, ela permite que todo o processo ensino-aprendizagem aconteça com mais intensidade, o que a relaciona ao favorecimento e a maiores facilidades nos processos de formação cognitiva e intelectual.

$\mathrm{Na}$ escola o ensino e a aprendizagem ocorrem como trocas professor-aluno em ambos os sentidos, e permeiam uma rede de relações históricas, sociais, econômicas, pedagógicas, intelectuais e afetivas (FONTANA E CRUZ, 1999).

Para designar as relações interpessoais de afetividade em sala de aula foi criado o termo pedagogia do afeto, a qual consiste na introdução de fundamentações teóricas, técnicas e vivências que possibilitam a troca energética e o toque afetivo no processo de ensino-aprendizagem, de modo que as pessoas possam intercambiar a amizade, a ternura, a cooperação, o respeito mútuo, e tantos outros sentimentos positivos para fazer do ambiente escolar um espaço de bem-estar e realização pessoal (FRANÇA E DIAS, 2002).

Segundo Freire, não existe educação sem amor.
"Ama-se na medida em que se busca comunicação, integração a partir da comunicação com os demais (...)" (FREIRE, 1983)

Neste sentido, a educação afetiva consiste na construção de uma escola a partir do respeito, compreensão, moral e autonomia de idéias. Uma vez que se pretende capacitar sujeitos críticos, honestos e responsáveis, o desenvolvimento afetivo é fundamental para qualquer indivíduo. Com isso, a afetividade contribui para o desenvolvimento da aprendizagem de forma crítica e autônoma, pois a afetividade não se resume em manifestações de carinho físico, mas principalmente em uma preparação para o desenvolvimento cognitivo (RIBEIRO, 2010).

As crianças, seja na Educação Infantil ou no Ensino Fundamental, devem e precisam ter oportunidade de desenvolver sua afetividade na escola, mesmo que muitas vezes elas não tenham esse ambiente propício em seu lar, pois a falta da mesma leva à rejeição aos livros, à carência de motivação para a aprendizagem e à ausência de vontade de crescer.

\section{Desenvolvimento psico-afetivo através das} relações sócio-familiares 
A afetividade está ligada aos sistemas de valores que são formados desde que a criança é pequena. Ela insere-se em um contexto que é relacionado aos vínculos afetivos que a criança recebe de quem as cuida e desenvolve a partir do seu nascimento (LAMB, 1987 apud WEINTEN, 2002; TOGNETTA, 2003; GONÇALVES, 2003; ANDRADE, 2007).

Da mesma forma, animais jovens freqüentemente desenvolvem fortes vínculos com os pais logo após o nascimento. O vínculo assegura que a prole permaneça próxima para que possa ser nutrida, protegida e ensinada a se comportar de forma adaptativa (LEVINE, BANICH E KOCH-WESER, 1988). Yarrow, Rubinstein e Pederson (1975) destacaram que os seres humanos permanecem imaturos, desamparados e, portanto, dependentes dos adultos que os rodeiam por mais tempo que qualquer outro animal. Esta estimulação social responsiva aumenta o contato visual, o balbucio e os sorrisos, estabelecendo uma vinculação mais estreita entre pais e filhos.

Quando o bebê está ainda na vida intra-uterina, já começa a sentir o pulsar do coração da mãe, os barulhos e todos os sustos que a mãe leva. Depois que o bebê nasce não é possível distinguir se suas expressões são sensações ou sentimentos. Exatamente porque, na verdade, tais sentimentos que compõem o ser humano, estão ainda sendo formados e serão formados, de fato, nas relações. As trocas que ele estabelece no meio é que vão fazer com que esses sentimentos sejam diferenciados das sensações (TOGNETTA, 2004).

Para Maturana (2004), a mãe e o bebê se encontram na linguagem e no brincar, ou seja, na congruência de uma relação biológica, em uma plena aceitação da corporeidade. Assim, o bebê se confirma como um ser biológico, no decorrer de seu crescimento como um bebê humano, em interações humanas. Porém, Alencastro (2009) alega que a mãe pode não se encontrar com o bebê na brincadeira, por razão de suas expectativas, desejos, aspirações ou ilusões.

"Vai por mal caminho o bebê cuja mãe trate dele, ainda que o faça na melhor das intenções, acreditando que os bebês pouco mais são, no princípio, do que um feixe de fisiologia, anatomia e reflexos condicionados. Sem dúvida, esse bebê será bem alimentado, poderá alcançar uma boa saúde física e ter um crescimento normal, mas se a mãe não souber ver no filho recém nascido um ser humano, haverá poucas probabilidades de que a saúde mental seja alicerçada com uma solidez tal que a criança, em sua vida posterior, possa ostentar uma personalidade rica e estável, suscetível não só de 
adaptar-se ao mundo, mas também participar de um mundo que exige adaptação." (WINNICOTT, 1971)

"Se essa negação do bebê só acontece de modo ocasional, não surge nenhuma dificuldade fundamental no seu crescimento. Porém, se o desencontro entre a mãe e o bebê se torna sistemático, prejudica-se o crescimento deste. Surge então uma criança com alterações fisiológicas e psíquicas." (MATURANA, 2004)

\section{A influência da afetividade no} desenvolvimento psicossocial e cognitivo

No estudo do desenvolvimento epistemológico do homem, ou seja, como se constrói o conhecimento humano, Piaget (1976) descreveu que o desenvolvimento cognitivo é aprendido em um processo continuado, dividido em quatro estágios: sensório-motor (0 a 2 anos), pré-operacional (2 a 7 anos), operações concretas (7 a 12) e operações formais (12 em diante).

Para Piaget (1976), o afeto pode acelerar ou retardar o desenvolvimento das estruturas cognitivas. $\mathrm{O}$ afeto acelera $\mathrm{o}$ desenvolvimento das estruturas, no caso de interesse e necessidade, e retarda quando a situação afetiva é obstáculo para o desenvolvimento intelectual. A afetividade não explica a construção da inteligência, mas as construções mentais são permeadas pelo aspecto afetivo. Toda conduta tem um aspecto cognitivo e um afetivo, e um não funciona sem o outro.

Na psicogenética de Henri Wallon, a dimensão afetiva ocupa lugar central, tanto do ponto de vista da construção da pessoa quanto do conhecimento. Ambos se iniciam em um período denominado impulsivo-emocional e se estende ao longo do primeiro ano de vida. Ele afirma que o ser humano é, logo que sai da vida puramente orgânica, um ser afetivo. Neste momento a afetividade reduz-se praticamente às manifestações fisiológicas da emoção, diferenciando-se lentamente à vida racional. Ao longo do trajeto, afetividade e inteligência alternam preponderâncias e a afetividade reflui para dar espaço à intensa atividade cognitiva assim que a maturação põe em ação o equipamento sensório-motor necessário à exploração da realidade (DANTAS, 1992).

Nos momentos dominantemente afetivos do desenvolvimento, o que está em primeiro plano é a construção do sujeito, que se faz pela interação com os outros sujeitos, à custa da aquisição de técnicas elaboradas pela cultura. Os primeiros sentimentos sociais bem definidos surgem durante o desenvolvimento pré-operacional. Crianças mais novas 
mostram afeição e têm sentimentos de gostar e não gostar, mas a representação e particularmente a linguagem falada são instrumentais no desenvolvimento dos sentimentos sociais. Assim, pela primeira vez, os sentimentos podem ser representados e recordados, e as experiências afetivas acabam tendo como efeito o de poder durar mais do que as próprias ocorrências vividas (WADSWORTH, 1997).

França e Dias (2002) afirmaram que a afetividade da criança pré-operatória é manifestada a partir dos sentimentos de antipatias e simpatias ligadas a valorização dos outros e do aparecimento de sentimentos de inferioridade e superioridade ligados a autovalorização. A autovalorização é compreendida como uma troca afetiva consigo mesmo, cujas raízes (confiança ou angústia) estão no período sensório-motor. A criança pré-operatória já se percebe como um todo e, dessa maneira, seus sentimentos são mais duradouros. Ela já começa a julgar-se então superior ou inferior aos outros, e suas relações passam a ser regidas por sentimentos de simpatia ou de antipatia (PIAGET, 1976).

Piaget atribuiu nítida importância às relações sociais entre as crianças para o desenvolvimento afetivo e intelectual. Quando as relações infantis ocorrem entre iguais, a cooperação torna-se uma possibilidade real. Embora o comportamento parcialmente socializado seja evidente desde o início da linguagem falada, Piaget afirma que é em torno dos 7 ou 8 anos (com o nascimento das operações cognitivas e com o fim do egocentrismo pré-operacional), que ocorre o progresso sistemático da cooperação (WADSWORTH, 1997).

Notadamente, a criança nesta fase, vivencia situações no seu dia-a-dia que a levam a experimentar sentimentos de sucesso ou fracasso. Sucesso quando, por exemplo, ela consegue executar uma tarefa escolhida por ela ou quando consegue fazer algo com materiais de sucata e sua produção é valorizada. Fracasso quando, por exemplo, numa brincadeira na qual havia a necessidade de muita destreza física para ganhar, a criança não consegue se sair bem.

Estes fatores não influenciam apenas o desenvolvimento cognitivo, mas também o desenvolvimento afetivo. Durante o estágio operacional concreto, os afetos adquirem uma medida de estabilidade e consistência que não apresentavam antes. Em torno dos sete ou oito anos, emerge a conservação dos sentimentos e dos valores e as crianças tornam-se aptas a coordenar os seus pensamentos afetivos de um evento para outro. O pensamento afetivo é agora reversível. $\mathrm{O}$ desenvolvimento cognitivo, o desenvolvimento afetivo e o desenvolvimento social tornam-se inseparáveis. Portanto, quando são 
conceituados separadamente, não causa surpresa à existência de paralelos evidentes entre eles (WADSWORTH, 1997).

A afetividade, portanto, é de suma importância para a vida, tanto quanto a formação cognitiva ou o processo de conhecimento. A afetividade e a inteligência são dois aspectos inseparáveis no desenvolvimento e se apresentam de forma antagônica e complementar, pois se a criança tem algum problema no desenvolvimento afetivo isto acabará comprometendo seu desempenho cognitivo. $\mathrm{O}$ afeto é o estimulante, o que excita a ação e o pensamento é o fruto da ação (RIBEIRO, 2010).

\section{O papel dos grupos sociais no desenvolvimento das crianças}

Os seres humanos são criaturas sociais, animais que optam por viver entre outros da mesma espécie. Gradativamente a começar da lactância, adquirimos os comportamentos e conceitos que nos tornam adequados à vida em grupo. Este processo, conhecido por socialização, ocorre naturalmente à medida que pais e outras pessoas orientam-nos para comportamentos, valores, metas e motivos que a sociedade julga apropriados (DAVIDOFF, 2001).
Segundo Wallon (1975), o organismo é a primeira condição do pensamento, mas não é suficiente, porque o objeto de ação mental se desenvolve a partir do meio social em que a criança está inserida. Isso significa então que para Wallon a inteligência é organicamente social, ou seja, a cognição é como item da pessoa completa que só pode ser compreendida associada a ela. $\mathrm{O}$ indivíduo se desenvolve a partir das condições orgânicas e é resultante da relação entre o organismo e o meio social ao qual está inserido (RIBEIRO, 2010).

Isto ocorre, pois a resolução do complexo de Édipo leva a criança a dirigir seus interesses para outras pessoas que não os pais, preparando-a para estabelecer relações interpessoais fora do lar. Desenvolve a necessidade de pertencer a um grupo de iguais e de ser aceito pelos companheiros bem como a necessidade de sentir-se responsável e capaz de realizar feitos que recebam aprovação e lhe dêem um status no grupo. Aprende se poderá ser um líder, um auxiliar na liderança, um simples seguidor, um rebelde ou um alienado. Não é preciso dizer que a posição conseguida nesta micro-sociedade terá influências decisivas nos papéis sociais posteriormente desempenhados na vida adulta. O espírito grupal é muito desenvolvido nesta fase e o grupo é um poderoso auxiliar do ego individual na exteriorização de impulsos e na 
modificação de seus controles (D’ANDREA, 2000).

Segundo a ótica de Goldsmith e Harman (1994), a qualidade de vinculação pode ter conseqüências importantes no desenvolvimento subseqüente das crianças. Bebês com um vínculo relativamente seguro tendem a se tornar crianças alegres, capazes e com elevada auto-estima.

Lamb, Ketterlinus e Fracasso (1992); Turner (1991), afirmam que nos anos préescolares as crianças têm maior persistência, curiosidade, autoconfiança, liderança e melhores relações com seus companheiros. Jacobsen, Edelstein e Hofman (1994) também observaram uma relação entre vínculo seguro e desenvolvimento cognitivo mais avançado durante a infância e a adolescência.

Neste contexto, a escola, o professor e as relações interpessoais que ocorrem neste ambiente oferecerão estímulos base que influenciarão a estruturação tanto da cognição como do afeto nas fases iniciais de educação em que o psiquismo está sendo formado.

\section{Desenvolvimento Social - O papel da escola}

O ambiente escolar obviamente pode influenciar de maneira positiva ou negativa esse processo de autovalorização, dependendo do tipo de relações que a criança estabelece com seus pares e com os adultos nesse ambiente.

Tognetta (2004) relatou que na escola tradicional, pelo fato de o trabalho ser realizado de forma coletiva o tempo todo, não há muitas oportunidades de ocorrerem trocas afetivas, devido à dinâmica de trabalho adotada. As atividades existentes em sala de aula são solitárias e, quando são oferecidos trabalhos e jogos que envolvam as crianças, geralmente são mais competitivos do que cooperativos, favorecendo, dessa forma, as trocas deficitárias e, por conseguinte, a antipatia. É importante, neste sentido, que o professor promova o sentimento de amizade, simpatia e auxílio mútuo entre as crianças, visto que motivação para cooperar depende do fato de as crianças se importarem com o relacionamento.

A simpatia implica em compartilhar valores e interesses comuns, isto é, a mútua valorização. Para gerar este tipo de sentimento, as pessoas têm que se conhecer, trocar idéias, interagir, compartilhar seus interesses e valores. Numa situação escolar, na qual não se permitem conversas, troca de pontos de vista, o desenvolvimento deste tipo de sentimento torna-se impossível (TOGNETTA, 2004).

Moreno et al. (1999) relataram que a afetividade ajuda na construção do 
conhecimento do meio natural, social e cultural. E este conhecimento ocupa um lugar muito importante no primeiro ciclo do Ensino Fundamental, uma vez que o alunado se apropria de conhecimentos, hábitos, formas de atuar, de se comunicar e de conceber o mundo, a partir do ambiente que o rodeia.

França e Dias (2002) afirmaram que ao se fundamentar na psicologia transpessoal é possível aplicar uma determinada didática em sala de aula para permear de afetividade as relações docentes e discentes, e melhorar com isso a qualidade dos relacionamentos e a produtividade em sala de aula.

Segundo Tognetta (2004), a escola atualmente pretende contribuir para a equilibrada formação da personalidade do aluno e sua integração ao ambiente sóciocultural, através do ajustamento de seus sentimentos, atitudes e ideais aos do grupo a que o mesmo pertence.

No entanto, Molon e Santos (2008) relataram que atualmente a compartimentalização entre cognição e emoção é fato presente nas escolas. O cenário educativo tem se ocupado pouco com aspectos mais voltados para as áreas das relações interpessoais e dos afetos e emoções. Fato este que corresponde às exigências, talvez contraditórias de uma civilização moderna, que propõe a separação entre o mundo sentimental e o racional e intelectual.

Neste contexto, a falta de educação da própria vida afetiva e o desconhecimento das formas de interpretação e de respostas adequadas perante atitudes, condutas e manifestações emotivas das demais pessoas, deixa os alunos e alunas à mercê do ambiente que os rodeia e no qual abundam modelos de resposta agressiva, descontrolada e ineficaz diante dos conflitos interpessoais, que, com freqüência, se apresentam em todas as formas de convivência social (MORENO et al., 1999).

A escola não pode esquecer-se de para que as atitudes das pessoas possam ser virtuosas, é preciso muito mais do que a tomada de consciência em termos cognitivos.

"Essa tomada $\begin{array}{r}\text { de } \\ \text { precisa }\end{array}$
consciência ressupor, também, outro
lado do ser humano, que é a
afetividade. Nenhum
homem pode ter ausentado
essa dimensão afetiva. Não
é só necessidade do
professor de educação
infantil trabalhar com os
aspectos afetivos, mas sim
de todo e qualquer
professor, porque a
afetividade não está só
presente no aluno da pré-
escola, está presente no ser
humano. E o ser humano é
aluno de maternal ao
terceiro ano do ensino
médio, da faculdade, ou de


quaisquer instituições ou programas de ensino." (TOGNETTA, 2004)
Chalita (2001) ressaltou que o grande pilar da educação é, sem dúvida, a habilidade emocional.

"Não é possível desenvolver a habilidade cognitiva e a social sem que a emoção seja trabalhada. A emoção trabalha com a libertação da pessoa humana. A emoção é a busca do foco interior e exterior, de uma relação do ser humano com ele mesmo, e com o outro, o que dá trabalho, demanda tempo e esforço, mas é o passaporte para a conquista da autonomia e da felicidade." (CHALITA, 2001)

Na escola, Tognetta (2004) destacou a relevância de se estudar as virtudes emocionais:

"Tratar delas na escola fazse uma necessidade ainda maior, manifestada por educadores que buscam atender a um objetivo único, claro, preciso, à formação de cidadãos conscientes, pessoas respeitosas $\mathrm{e}$ solidárias. Porém, essa não é uma tarefa fácil. Falar de sentimentos é favorecer sua manifestação, bem como a reflexão sobre os estados de ânimo e as relações intrapessoais que podem provocá-los, amenizá-los ou acentuá-los."

\section{O professor como agente formador social}

Deve fazer parte da vida do ser humano, o respeito ao próximo, e a escola como contribuinte na formação cidadã de seus alunos, precisa proporcionar relações que indiquem essa postura, que muitas das vezes parte de dentro da própria sala de aula com o diálogo existente entre mediador e educando (MACEDO, 2011). Assim, fica claro que além da escola e da família, o professor neste contexto, apresenta papel fundamental no desenvolvimento social da criança.

Isto ocorre, pois durante o período de latência, a maioria das crianças freqüenta a escola, e após os seis anos, os pais deixam a cargo dos professores grande parte da educação da criança. Como transmissor de conhecimentos, o professor passa a ser a pessoa mais importante na vida da criança depois dos pais e ela procura identificar-se com ídolos. Por isso, é importante que o professor, ídolo vivo e mais próximo, contenha em sua personalidade elementos desejáveis para identificação. Decepções com o professor podem ser tão dolorosas como decepções com os próprios pais (D’ANDREA, 2000). 
Em relação à isso, Arruda e Borges

(2011) descreveram:

"A aprendizagem e a afetividade na relação entre criança e professor devem caminhar juntas, pois é a partir da afetividade que a criança passa a ter confiança no professor e com isso algumas barreiras são superadas como por exemplo a dificuldade da criança em aprender determinado conteúdo, bem como desenvolver determinada atividade. É com diálogo, carinho que o professor constrói caminhos para chegar ao universo da criança a fim de ajudá-la a superar suas dificuldades."

Segundo De Paula e Faria (2010) todo ser humano precisa de limites, mas de carinho e amor também. Um educando aprende o que é respeito e respeita a partir do momento em que vê o educador como um amigo que tem e espera respeito, como alguém que se preocupa de verdade com ele e que the mostra os caminhos.

Assim, Molon e Santos (2008)

acreditam que:

“... o professor ao estabelecer um clima de confiança e uma atitude de respeito com o aluno passa a ser um grande mediador das aprendizagens destes. Uma das fontes motivacionais do ensino e da aprendizagem está no vínculo estabelecido entre educador e educando.
A afetividade é um fator que precisa ser fortalecido nas relações educacionais dentro e fora da escola."

Chalita (2001) destacou a importância da afetividade no tratamento dos alunos, pois, segundo ele, só há educação onde há afeto, onde experiências são trocadas, enriquecidas, vividas. O professor que apenas transmite informação não consegue perceber a dimensão do afeto na aprendizagem do aluno. O aluno precisa de afeto, de atenção. A família cada vez mais desestruturada gera filhos ainda mais complicados, tristes, ressequidos, carentes de um mestre que estenda a mão e não tenha medo de dar amor. Não se quer com isso desprezar a importância dos pais, nem tentar cobrir sua ausência e indiferença na vida dos filhos. Entretanto, como não dá para reclamar apenas, e alguma coisa precisa ser feita, que o professor amenize esse sofrimento $\mathrm{e}$ auxilie o desenvolvimento harmônico do aluno.

Ribeiro (2010) destaca que cabe a escola, mas principalmente ao educador, uma importante função social, devendo compreender o aluno no âmbito da sua dimensão humana, tanto afetiva quanto intelectual, já que a criança depende da qualidade da interação com o meio social para se desenvolver integralmente. 
“(...) percebe-se que há uma eminente necessidade, principalmente por parte dos educadores, de buscar conhecimento que trate sobre o tema da afetividade, pois este tema colabora para o desenvolvimento humano, visto que é na escola que a criança passa boa parte do seu tempo. O educador precisa entender a necessidade e ficar atento às atitudes das crianças para assim colaborar para o sucesso escolar e da vida do educando." (RIBEIRO, 2010)

D’Andrea (2000) em uma crítica construtiva ressaltou que o professor ideal seria aquele que além dos conhecimentos intelectuais, tivesse uma personalidade sem muitos conflitos, uma vida familiar satisfatória e fosse capaz de orientar seus alunos em outros assuntos além dos relacionados às matérias que ensina, pois infelizmente, não é raro as crianças encontrarem mestres desajustados, infelizes, mais preocupados com sua situação econômica ou social do que com os alunos. Alguns inclusive têm aversão por crianças ou se demonstram algum interesse, o fazem de forma a expressar favoritismo.

Não se defende a hipótese de que como requisito para o estudo e formação de professores, os mesmos devam ser seres humanos banidos de problemas, situações familiares conflitantes, tampouco sejam pessoas fundamentalmente caridosas. Mais ainda, sabe-se da pouca valorização monetária atual em nosso país para esse profissional que carrega consigo uma das tarefas mais difíceis e desafiadoras: a educação de seres em formação. Porém espera-se deles o mínimo de paixão não só pelo objeto de ensino, mas pelos sujeitos ensinados. Deseja-se um mínimo de empatia, um ver além do que o aluno expressa, manifesta ou deixa a desejar, seja em tarefas, domínios ou comportamento. Pretende-se um ambiente seguro, em que as fases sejam vivenciadas sob uma ótica construtivista de estímulos adequados, em que não apenas as informações são repassadas, mas o ensino é encarado como algo passivo de ser vivido. Não apenas na infância ou adolescência, contudo em qualquer situação e idade que requeira uma atitude cidadã e uma recordação de como operações técnicas aliadas à afetividade construíram um caráter, uma mente saudável, um ego seguro.

\section{Considerações Finais}

A afetividade acompanha o indivíduo fisiologicamente desde a concepção e fundamenta as fases psíquicas infantis que se seguem. $\mathrm{Na}$ fase escolar, a afetividade exerce 
coadjuvação no desenvolvimento cognitivo e intelectual e intercambia as relações sociais que estão se formando.

Nesta etapa os vínculos desenvolvidos poderão influenciar e determinar mudanças na construção da personalidade diante da socialização mesmo que o indivíduo não tenha recebido relações afetivas desde o nascimento, uma vez que não somos meramente 'moldados' ou passivos ao mundo. Nós agimos sobre o mundo e ainda, ao longo da vida convivemos com pessoas com as quais estabelecemos relações que podem ser tão significativas para a construção da personalidade quanto as primeiras relações sociais.

Entende-se, portanto, que a afetividade e a sensibilidade do educador, acima de tudo, irão permear autonomia, sucesso e realizações individuais e coletivas aos indivíduos enquanto seres humanos (no sentido literal da palavra) e cidadãos conscientes de seu papel na sociedade.

Além disso, elemento essencial na efetivação da aprendizagem é uma autoestima positiva, pois todo indivíduo precisa sentir-se capaz de pensar e agir, e ver-se como merecedor de felicidade. A auto-estima nos diz Claret (1995), é uma necessidade humana, que contribui essencialmente para o processo vital.
Assim, o respaldo de afetividade em todos os aspectos da vida seja social, profissional e pessoal, inclusive por toda a vida escolar fará com que o mesmo consiga atingir a realização plena dos seus ideais, pois conforme Rossini (2005), "se a criança está feliz, ela aprende, ela faz".

\section{Referências}

ALENCASTRO, C.E. As relações de afetividade na Educação Infantil. Trabalho de Conclusão de Curso. Universidade Federal do Rio Grande do Sul, Faculdade de Educação. Porto Alegre. 34p.; 2009.

ANDRADE, A.S. A influência da afetividade na aprendizagem. Monografia. Unievangélica Centro Universitário. Brasília. 50p.; 2007.

ARRUDA, D.E.P.; BORGES, S.N.O. Aprendizagem no momento com o brincar. IV EDIPE - Encontro Estadual de Didática e Prática de Ensino. 2011.

BOSSA, N. A. A. A psicopedagogia no

Brasil: Contribuições a partir da Prática. 2 ed. São Paulo: Artmed, 2000.

CAMPOS, D. M. S. Psicologia da

Aprendizagem. 33 ed., cap. VII, p. 68-74.

Petrópolis: Vozes, 2003.

CHALITA, G. B. I. Educação: A solução está no afeto. 7 ed. São Paulo: Gente, 2001.

CLARET, M. O Poder da Auto-Estima. São Paulo: Ed. Martin Claret Ltda. Coleção: O poder do poder, 1995. 
D'ANDREA, F. F. Desenvolvimento da Personalidade: Enfoque psicodinâmico. 14 ed. Rio de Janeiro: Bertrand Brasil, 2000.

DANTAS, H. A. Afetividade e a construção do sujeito na psicogenética de Wallon. In: TAILLE, Y. D. L.; OLIVEIRA, M. K.; DANTAS, H. Piaget, Vygotsky, Wallon: Teorias Psicogenéticas em Discussão. 18 ed., p.85-97. São Paulo: Summus, 1992.

DAVIDOFF, L. L. Introdução à Psicologia. 3 ed., cap. 10, p.442-5. São Paulo: Makron Books, 2001.

DE PAULA, S.R.; FARIA, M.A. Afetividade na aprendizagem. Revista Eletrônica Saberes da Educação. FAC, São Roque, v.1, n.1, 2010.

FONTANA, R. A. C.; CRUZ, M. N. Psicologia do trabalho pedagógico. São Paulo: Saraiva, 1999.

FRANÇA, C.; DIAS, V. A pedagogia do afeto. Revista Humanidades - Pedagogia. 1 ed. São João da Boa Vista: UNIFEOB, 2002. FREIRE, P. Educação e Mudança. Tradução de Moacir Gadotti e Lílian Lopes Martin. Rio de Janeiro: Ed. Paz e Terra, Coleção Educação e Comunicação, v.1, 1983.

GONÇALVES, M.F.C. Educação escolar: Identidade e diversidade. Florianópolis: Pioneira, 2003. (p.69-96).

GOLDSMITH, H.H.; HARMAN, C. Temperament and attachment: individuals and relationships. Current Directions in Psychological Science, v.3, p.53-57, 1994.

JACOBSEN, T.; EDELSTEIN, W.; HOFMANN, V. A longitudinal study of the relation between representations of attachment in childhood and cognitive functioning in childhood and adolescence. Developmental Psychology, v.30, p.112124, 1994.
LAMB, M.E. The Father's role. Cross Cultural Perspectives. Lawrance Erlbaum Associates, 1987. In: WEINTEN, W.

Introdução à Psicologia: Temas e variações. 4 ed., cap. 11, p. 316-7. São Paulo: Pioneira Thomson, 2002.

LAMB, M.E.; KETTERLINUS, R.D.; FRACASSO, M.P. Parent-child relationships. In: BORNSTEIN, M.H.; LAMB, M.E.

Developmental psychology: An advanced textbook (Third edition). Hillsdale, NJ: Lawrence Erlbaum Associates, p.465-518, 1992.

LEVINE, S.C.; BANICH, M.T.; KOCHWESER, M.P. Face recognition: a general or specific right hemisphere capacity? Brain and Cognition, v.8, p.303-325, 1988.

MACEDO, B.R.R. O papel da afetividade na relação professor aluno nos anos iniciais do Ensino Fundamental. Projeto de Monografia. Centro Universitário Metodista Isabela Hendrix. Belo Horizonte. 10p.; 2011.

MATURANA, Romicim Humberto \& Verden - Zöller. Amar e brincar: fundamentos esquecidos do humano do patriarcado à democracia. São Paulo: Palas Athena, 2004.

MOLON, K.S.; SANTOS, B.S. O papel do professor para o desenvolvimento afetivoemocional do aluno. III Mostra de Pesquisa da Pós-Graduação PUCRS. 2008.

MORENO, M.; SASTRE, G.; LEAL, A.; BUSQUETS, M. D. Falemos de sentimentos: A afetividade como um tema transversal. 1 ed., cap. 3, p.43-6. São Paulo: Moderna, 1999.

PAÍN, S. Diagnóstico e tratamento dos problemas de aprendizagem. 4 ed. São Paulo: Artmed, 1992.

PIAGET, Jean. A construção do real na criança. Rio de Janeiro: Zahar, 1976. 
RIBEIRO, L.P.L. Afetividade na Educação

Infantil: a formação cognitiva e a moral do sujeito autônomo. Monografia. Faculdade Alfredo Nasser, Instituto Superior de Educação. Aparecida de Goiânia. 27p.; 2010.

ROSSINI, M. A. S. Pedagogia Afetiva. 7 ed. Petrópolis: Vozes, 2005.

THUMS, J. Educação dos sentimentos. 160p. Porto Alegre: Sulina, 1999.

TOGNETTA, L. R. P. A construção da solidariedade e a educação do sentimento na escola: uma proposta de trabalho com as virtudes numa visão construtivista. FAPESP. Campinas: Mercado das Letras, 2004.

TURNER, J.C. Social Influence: Mapping social psychology.Buckingham: Open University Press, Milton Keynes, 302p.; 1991. VINHA, T. P. O educador e a moralidade infantil: uma visão construtivista. FAPESP. Campinas: Mercado das Letras, 2001.

WADSWORTH, B. J. Inteligência e afetividade da criança na Teoria de Piaget: Fundamentos do Construtivismo. 5 ed., cap. IV, p.89-117. São Paulo: Pioneira, 1997.

WALLON, Henri. Psicologia e Educação da Infância. Lisboa: Editorial Estampa, 1975.

WEINTEN, W. Introdução à Psicologia:

Temas e variações. 4 ed., cap. 11, p. 316-7.

São Paulo: Pioneira Thomson, 2002.

WINNICOTT, D.W. A criança e o seu

mundo. Rio de Janeiro: Zahar Editores, 1971.

YARROW, L.J.; RUBINSTEIN, J.L.; PEDERSON, F.A. Infant and environment: early cognitive and motivational development. New York: Halsted Press, 1975. 